\title{
Using a traction battery as thermal storage
}

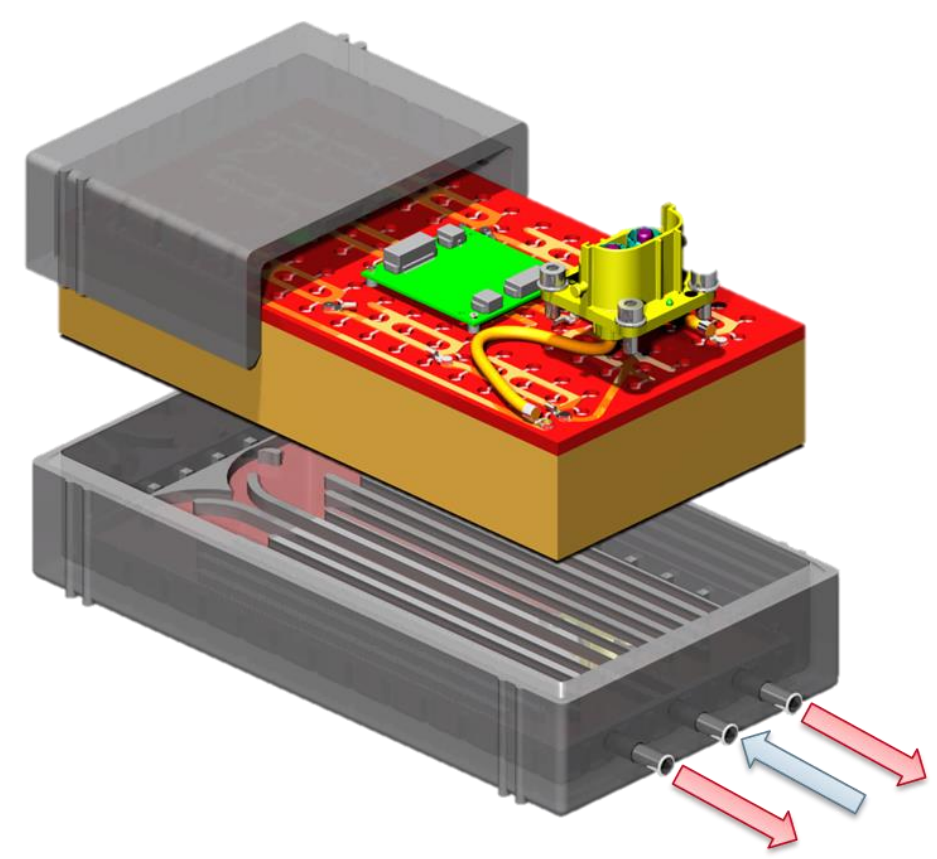

(c) RWTH Aachen University

\section{Preface}

The driving range of EVs decreases significantly at low outside temperatures. In order to reduce the dependency of the driving range on the ambient conditions, the partners DENSO, Fraunhofer, IKA (RWTH Aachen) and the Virtual Vehicle Research Center work on a solution consisting of a compact refrigeration unit and a battery system with PCM, capable of storing thermal in addition to electric energy.

Content

1) Motivation

Current EVs have the problem of a strongly varying driving range depending on the ambient conditions. At winter conditions and the use of resistance heating the driving range can drop by $50 \%$. This is caused by the energy consumption for heating and dehumidification as well as the decreasing efficiency of the lithium-ion battery. The use of the refrigerant cycle as heat pump is a promising solution for this issue, but icing of the front-end heat exchanger is decreasing the performance and efficiency of the system at low outside temperatures.

In the EU-funded research project "OPTEMUS“ the partners DENSO, Fraunhofer, IKA RWTH Aachen University and the Virtual Vehicle Research Center (project coordinator) are developing a solution with a compact refrigeration unit, which enables the use of different heat sources. Because of its high mass the traction battery has also a high thermal capacity. Thus, a concept for the usage of the lithium-ion battery as thermal storage was developed in the project. This concept enables a preconditioning of the battery during charging. In combination with a "predictive" preconditioning functionality, which considers for instance the departure time as well as the expected weather conditions, the battery can be tempered adequately. The stored heat can then be use by the heat pump system for the heating of the cabin, which is much more efficient than resistance heating and thus increases the driving range. Also for summer conditions the battery can be preconditioned to lower temperatures, which reduces the energy demand for battery cooling and minimizes the aging of battery cells caused by high temperatures. 


\section{2) Compact Refrigeration Unit}

The compact refrigeration unit (CRU) from DENSO is a water-to-water system that consists of a compressor, two heat exchangers and an expansion valve in the same housing (see Figure 1). On the evaporator (chiller) side, heat is withdrawn from the coolant circuit and transferred to the coolant that flows through the condenser. The two emerging temperature levels can be used for the thermal management in the vehicle, i.e. the "cold" and "hot" coolant can be redirected by means of valves in the vehicle in order to combine heat sources and heat sinks in an energy efficient way. Additionally, excessive heat can be released or taken from the ambient via an exterior heat exchanger.

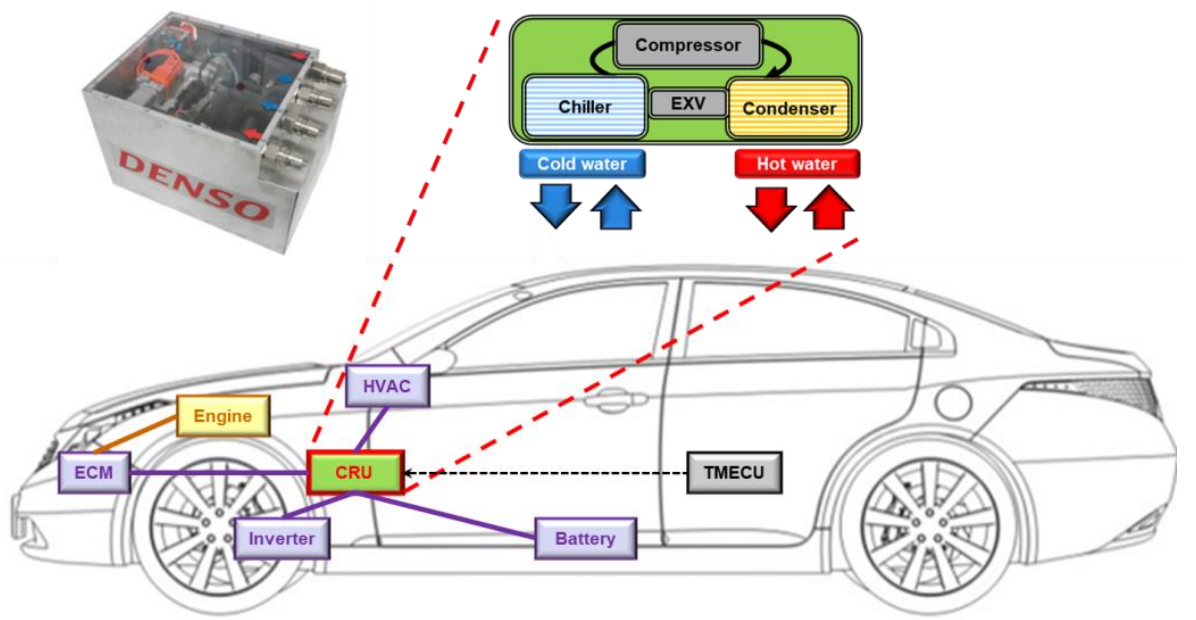

Figure 1: Compact Refrigeration Unit (CRU) from DENSO in the vehicle (@ Virtual Vehicle)

This system enables heat pump operation mode, where electric components as well as the battery are cooled and this heat is used for heating up the passenger cabin. If there is the demand to heat the battery and the cabin, the ambient air can be used as heat source. Additionally, an efficient dehumidification process for the cabin air can be provided with the heat pump system. Therefore, the fresh air is cooled and dehumidified through the "cold" coolant circuit and afterwards heated by the "hot" coolant circuit. Also for cooling mode this system enables the appropriate combination of heat sources and heat sinks in the vehicle.

3) Battery with PCM and thermally insulated housing

At low temperatures, the ambient air does not provide sufficient heat, in order to use the heat-pump efficiently for passenger cabin heating. Additionally, the performance of state-of-the-art Li-lon-tractionbatteries is significantly lower at low resp. high temperatures. A battery temperature of $0{ }^{\circ} \mathrm{C}$ results in a $20 \%$ decrease of battery efficiency compared to a battery temperature of $20{ }^{\circ} \mathrm{C}$ [2]. The battery concept developed at IKA, transfers heat over the system boundary via a water-glycol-cycle, which enables for heating and cooling of the battery and provides heat for the cold-water-cycle of the heatpump. At low temperatures, the battery can be heated by the water-glycol-cycle to improve the charging performance of the battery. To improve the thermal stability of the battery and to enhance the thermal capacity of the battery, a unique phase-change-material (PCM) is used inside the battery modules. The battery system consists of 16 modules with a voltage of $48 \mathrm{~V}$, which are interconnected in two strings of eight modules each. This results in a total capacity of $24.9 \mathrm{kWh}$ at a nominal system voltage of $345.6 \mathrm{~V}$. Figure 2 shows a schematic layout of such a battery module. 


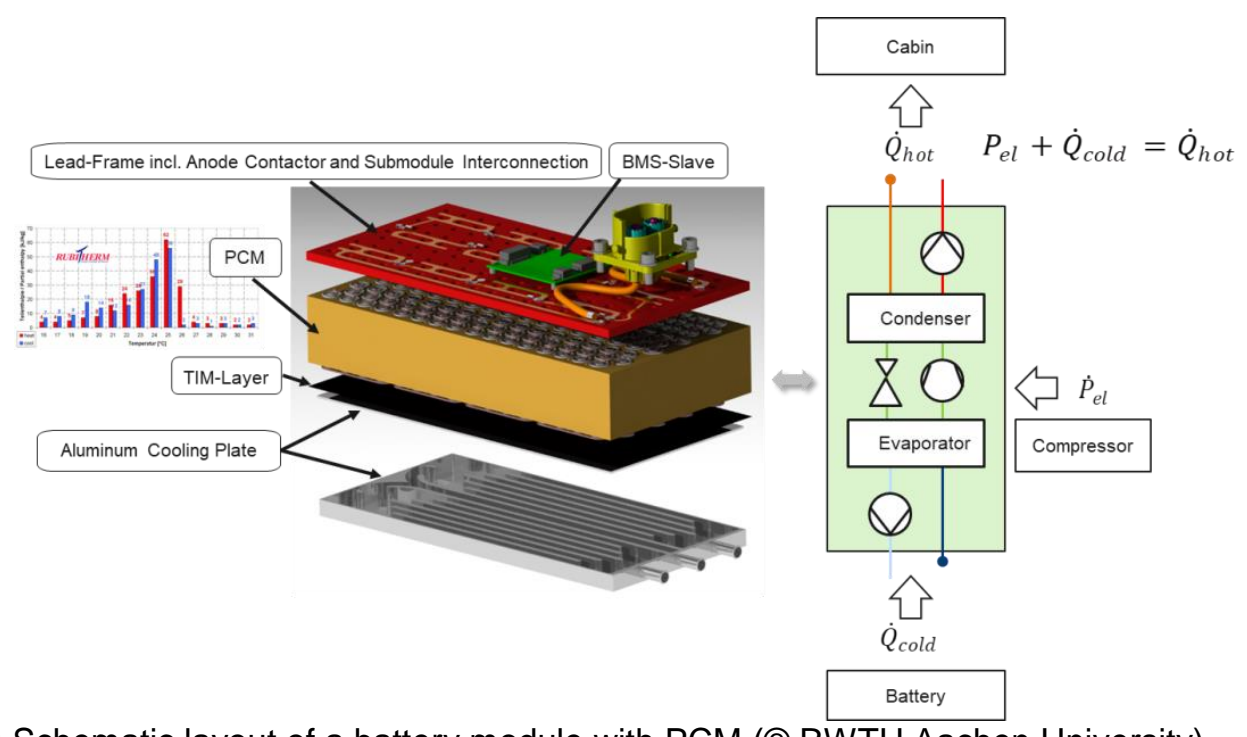

Figure 2: Schematic layout of a battery module with PCM (@ RWTH Aachen University)

The OPTEMUS battery module consists of 144 Li-lon cells of the type 18650. The resulting empty spaces between the cells are filled with PCM. To ensure an equal temperature distribution, all cells stand upright on a common cooling plate, which was flow optimized using 3D-simulation.

Between $35-15^{\circ} \mathrm{C}$ battery temperature, $1.7 \mathrm{kWh}$ of heat can be transferred into the water-glycol-cycle with a maximum heat transfer rate of $1.9 \mathrm{~kW}$. The maximum heat transfer rate is limited by the thermal conductivity of the PCM, which is increased by $400 \%$, due to the addition of boron nitride particles, while maintaining the same level of electrical insulation [3]. In addition, the thermal contact of the PCM could significantly be improved, due to the installation of copper pins, as can be seen in Figure 3

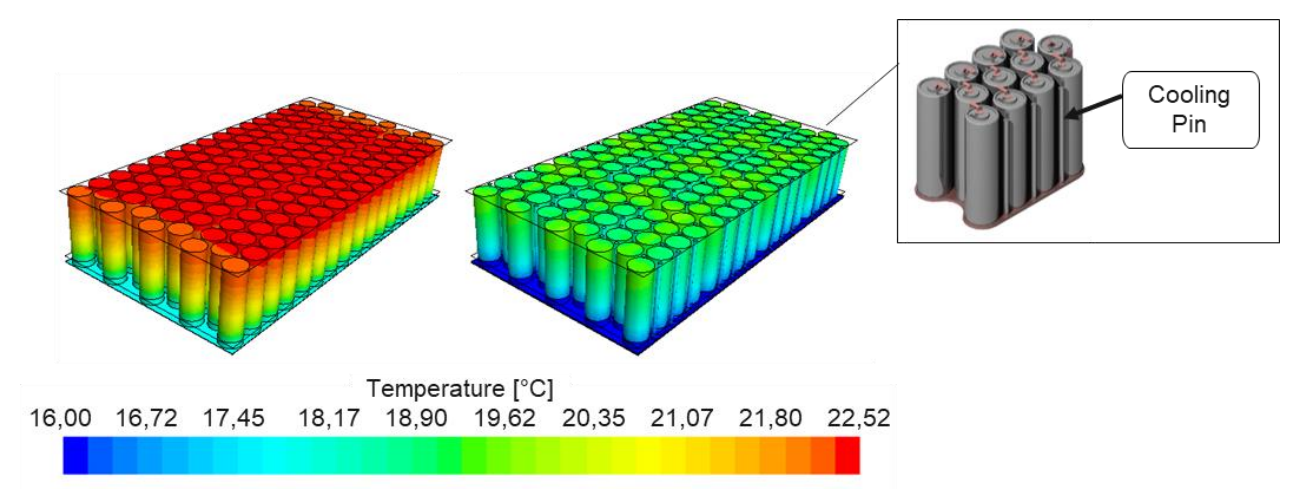

Figure 3: Temperature distribution inside the battery module without (left) and with (right) cooling pins (C) RWTH Aachen University)

Figure 3 shows the temperature distribution inside the battery module at the end of a 15-minute charge at maximum charging rate, which results in a heat generation of $0.83 \mathrm{~W} / \mathrm{cell}$. The initial temperature of the battery was $25^{\circ} \mathrm{C}$, during the entire charge the cooling plate temperature was maintained at a constant $15^{\circ} \mathrm{C}$. Due to the improved thermal contact of the PCM the maximum axial temperature difference of the cells as well as the average cell temperature inside the battery module is significantly lower. In further simulations, IKA proved that even without cooling the OPTEMUS-battery is capable of absorbing the total amount of heat, dissipated during a fast charge at room temperature, without reaching critical temperatures or temperature gradients. Even at significantly higher initial temperatures, the use of PCM shows good potential for homogenization of the cell temperatures, so that the battery temperature can be controlled with minimum heat transfer via the cooling plate.

An experimental test series was conducted in order to analyze the thermal insulation of the novel housing. Therefore, an aluminum housing as reference as well as a fibre-reinforced plastic (FRP) sandwich housing have been manufactured (see Figure 4). Battery sub-modules have been built-up with both housings and 40 round cells of the 18650 type, two of which have been equipped with temperature sensors. After a preconditioning to $23^{\circ} \mathrm{C}$, these modules were cooled down to $-10^{\circ} \mathrm{C}$ in a climatic chamber. During the test the cool-down rate until the cells reach $2{ }^{\circ} \mathrm{C}$ was measured. It was 
found that using a TP-FRP sandwich housing the cool-down rate could be reduced by $250 \%$ compared to an aluminum housing, thus significantly increasing the insulation.

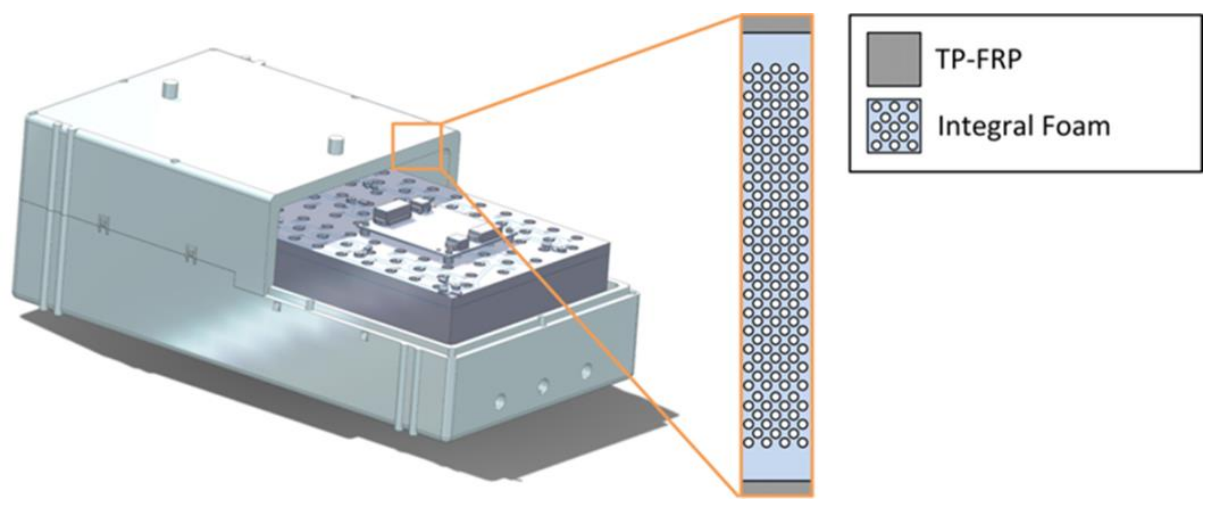

Figure 4: Battery module housing with sandwich structure consisting of insulating integral foam and high strength TP-FRP facesheets (@ Fraunhofer LBF)

The TP-FRP sandwich housings were manufactured by use of a hybrid injection moulding process based on foam injection moulding which was developed at Fraunhofer LBF. At this, unidirectionally glass fiber reinforced tapes (UD-tapes) are overmoulded with a foamed polymer (Polypropylene). The resulting cellular foam structure was analyzed via computer tomography with respect to material and process parameters and optimized aiming at maximum foaming degrees as well as minimum foam cell volumes.

\section{4) Preconditioning}

The preconditioning of an electric vehicle offers two essential advantages: firstly, the comfort is improved because the passengers do not enter into a cold or hot cabin; secondly, the drop of electric range is reduced by lowering of the compressor power (with low COP) when entering or driving of a non-conditioned vehicle. The preconditioning can also be applied to the battery to achieve an optimal battery temperature when driving away, especially in cold winter conditions, which improves the electric range and the battery life. In addition, the heat stored in the battery can also be used for heating the vehicle cabin, as already mentioned.

To enable an efficient thermal preconditioning of the cabin of electric vehicles, DENSO has developed an innovative solution that offers maximum comfort to the user with low energy consumption and increases the range of the vehicle [4]. The challenge is to find the optimum time to start the vehicle's preconditioning (heating or cooling of the cabin room) without significantly reducing the range of the vehicle (if the vehicle is not connected to a charging station). For this purpose, both a user-triggered (by means of an app) and a predictive algorithm have been developed, which foresees the driver behavior (approach to the vehicle) to ensure the timely preconditioning of the cabin room upon arrival of the driver. If the preconditioning function achieves the target temperature too early (i.e. before the driver arrives), some energy is unnecessarily consumed. On the other hand, if the vehicle has not yet reached the target temperature when the driver arrives, the desired comfort level will not be achieved. The predictive approach, however, increases the likelihood of false triggers (i.e. when the driver is approaching the car, although he does not intend to enter into it). These false alarms and the corresponding unnecessary energy waste must be avoided.

The pre-conditioning is provided through mobile communication. As shown in Figure 5, the user can control the preconditioning functionality with an app that communicates with the vehicle's Human Machine Interface (HMI) through a cloud server. The HMI sends the required information to the Thermal Management ECU (TMECU) through the CAN bus gateway (GW). After this, the high-level controller starts the optimized preconditioning process to reach the desired target temperature in the cabin room upon arrival of the driver. 


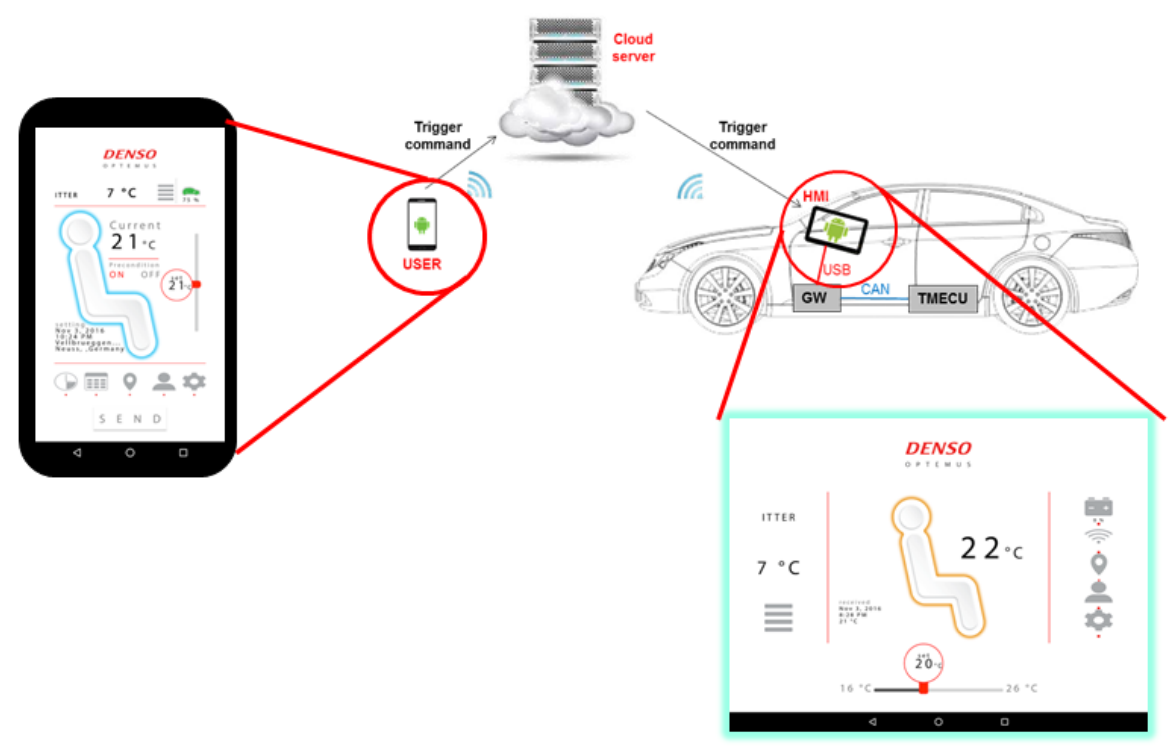

Figure 5: $\mathrm{HMl}$ and communication architecture of preconditioning (@ DENSO)

\section{5) Simulation results}

To quantify the impact of the described technologies on the energy consumption and the driving range, four different scenarios of passenger cabin heating at $-10^{\circ} \mathrm{C}$ ambient temperature are compared by means of simulation: in case 1 a PTC-heater heats up the passenger cabin from $-10^{\circ} \mathrm{C}$, in case 2 the passenger cabin is preconditioned to $20^{\circ} \mathrm{C}$ during battery charging. In the third case, the preconditioned passenger cabin is heated by the compact refrigeration unit, using the ambient air as heat source (average COP $=1.1$ ) and in the fourth case the battery is used as heat source (average $\mathrm{COP}=2.1$ ). Figure 6 (top left) shows that during the 30 minutes of the "Aachen Driving Cycle" at either starting temperature, the cabin heating initially operates at full load, due to its control strategy. For the preconditioned cabin, the heating control reduces power significantly earlier, which reduces the energy consumption from $2.06 \mathrm{kWh}$ to $1.18 \mathrm{kWh}$. The use of the CRU enables for additional energy savings: using the ambient air as heat source reduces the energy consumption to $1.07 \mathrm{kWh}$, using the battery as heat source further reduces the energy consumption significantly to $0.56 \mathrm{kWh}$ (Figure 6 top right). For the simulated A-segment vehicle this leads to an increased driving range from $93 \mathrm{~km}$ (case 1) to $108 \mathrm{~km}$ for case $2(+17 \%)$, to $111 \mathrm{~km}$ for case $3(+19 \%)$, to $123 \mathrm{~km}(+32 \%)$ in case 4 , when all technologies are applied (Figure 6 bottom right).
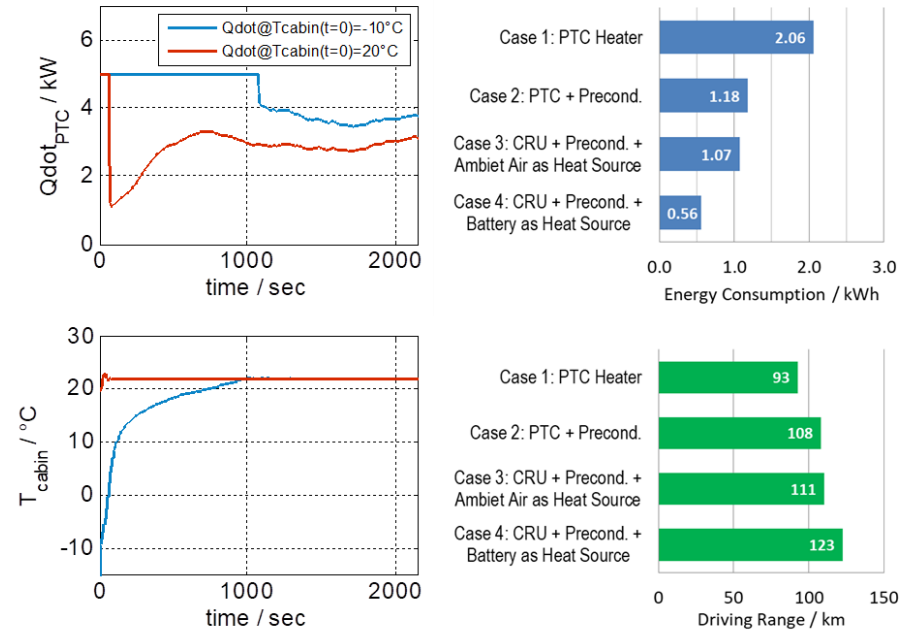

Figure 6: Power of the PTC-heater (top left) and cabin temperature (bottom left) with and without preconditioning (Case 1 in blue, Case 2 in red) as well as calculated energy consumption (top right) for the four defined cases and the impact on the driving range (bottom right) (@ Virtual Vehicle) 


\section{6) Conclusions and outlook}

The use of the compact refrigeration unit in combination with a battery with integrated PCM as heat storage enables together with preconditioning of the battery and the cabin a significant reduction of the energy consumption during driving. Simulation results for a 30 minute drive in heating mode at low outside temperatures $\left(-10^{\circ} \mathrm{C}\right)$ show a reduction of $1.5 \mathrm{kWh}$, which leads to an extension of the driving

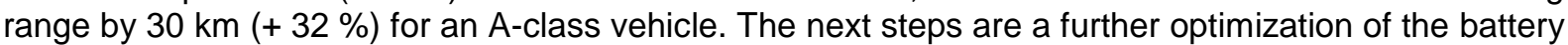
cooling loops as well as a reduction of the coolant volume (e.g. with the help of "dry battery modules" with a common cooling plate). Additionally, preconditioning will be enhanced with predictive functions, which consider the planned route as well as expected weather conditions.

\section{Acknowledgement}

The work reported in this article was funded by the European Union's Horizon 2020 research and innovation programme under grant agreement No. 653288. The authors thank the Co-authors Christoph Massonet (IKA), Markus Özbek (DENSO) and Werner Hünemörder (DENSO) for their contributions.

\section{References}

[1] A. Caldevilla, M. Özbek, W. Hünemörder, T. Györög, E. Hougard, M. Pintea, Efficient cabin and powertrain preconditioning for EVs with a water-to-water heat pump system, $12^{\text {th }}$ International Conference on Ecological Vehicles and Renewable Energies (EVER), Monaco, April 2017

[2] Kontinuierliches Design und Funktions-Benchmarking von Elektrofahrzeugen https://benchmarking.fka.de, 02/28/2017

[3] G. Mimberg, C. Massonet, Battery concept to minimize the climate-related reduction of electric vehicles driving range, $12^{\text {th }}$ International Conference on Ecological Vehicles and Renewable Energies (EVER), Monaco, April 2017

[4] A. Caldevilla, M. Özbek, W. Hünemörder, T. Györög, E. Hougard, M. Pintea, Efficient cloudbased cabin preconditioning for EVs with a compact heat pump system, EVS30 Symposium, Stuttgart, October 2017

About this article

First online: 1 . January 2018

DOI: https://doi.org/10.1007/s38311-017-0145-6

Publisher Name: Springer Fachmedien Wiesbaden 
1) Alois Steiner

is Co-Team Leader of the Group „Thermal Management \& Mobile Air Conditioning“ at Virtual Vehicle Research Center in Graz (Austria)

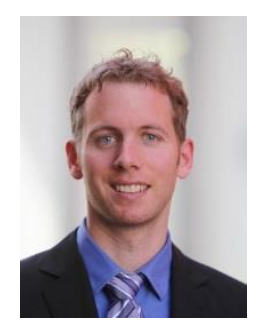

\section{2) Gero Mimberg}

is scientific assistant in the drivetrain department of the Institute for Automotive Engineering (IKA) of RWTH Aachen University

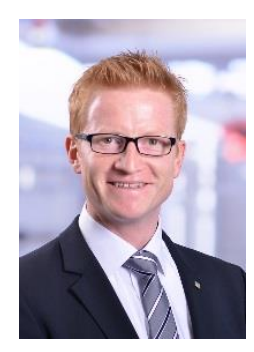

3) Felix Weidmann

is Team-Leader of "Composite Technologies" at Fraunhofer Institute for Structural Durability and System Reliability LBF, Division Plastics

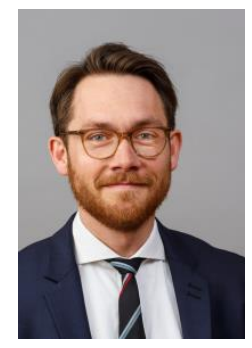

4) Andrés Caldevilla leads the Technology Trend Research and Evaluation at DENSO AUTOMOTIVE Deutschland $\mathrm{GmbH}$

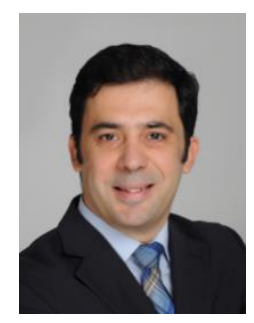

